Sociedad Botánica de México

CLAVE PARA LA LETERMINACION DE LAS TRIBUS MEXICANAS DE LA FAMILIA DE LAS ORQUIDEAS

(Adaptada de la clasificación de Pfitzer en Engler \& Prantl "Pflanzenfamilien".)

$$
\text { Por F. MIRANDA. }
$$

a) 2 estambres interiores ("Diandrae") ; a veces también fértil el estambre impar de los exteriores; labelo generalmente en forma de pantufla.

\title{
Tribu CYPRIPEDIEAE.
}

a) Por lo común sólo fértil el estambre imparz de los extẹriores ("Monandrae").

b) Polinias con caudículas o prolongaciones elásticas en su parte inferior ("Basitonae"); plantas terrestres con tubérculos radicales.

Tribu OPHRYDEAE.

b) Polinias sin caudiculas o con éllas saliendo del ápice ("Acrotonae"); antera fácilmente caediza.

c) Inflorescencia terminal en el simpodio ("Acranthae").

d) Hojas enrolladas en la yema; polén granuloso.

Tribu NEOTTIEAE. 
d) Hojas plegadas en la yema.

e) Sepalos más desarrollados que los pétalos; éstos a menudo invisibles desde el exterior.

\section{Tribu PLEUROTHALLIADEAE.}

e) Sépalos iguales o más pequeños que los pétalos.

f) Hojas no articuladas; 4 polinias céreas sin caudiculas.

Tribiu LIPARIDEAE.

f) Hojas articuladias.

g) $4-8$ polinias céreas, con caudículas.

Tribu LAELIEAE.

g) Polinias blandas, granulosas, sin caudículas; hojas de muchos nervios paralelos.

Tribu SOBRALIEAE.

c) Flores sobre ramos laterales especializados ("Pleuranthae").

h) Hojas arrolladas en la yema.

i) Sin seudobulbo o con seudobulbo formado por varios entrenudos del tallo.

j) Generalmente 8 polinias céreas con caudículas.

Tribu PHAJEAE.

j) 2 - 4 polinias, sin caudículas, pero con estipe.

k) Polinias con estipe corto y ancho.

Tribu CYRTOPODIEAE.

k) Polinias con estipe delgado y largo.

Tribu CATASETEAE.

i) Seudobulbo formado por un solo entrenudo del tallo.

1) Labelo carnoso.

Tribu GONGOREAE. 
1) Labelo membranoso.

m) Inflorescencia naciendo debajo del brote más reciente; polinias con estipe alargado o doble.

Tribu LYCASTEAE.

m) Inflorescencia naciendo encima del brote más reciente; polinias con estipe corto y ancho.

Tribu ZYGOPETALEAE.

h) Hojas plegadas en la yema.

n) Plantas simpodiales.

Tribu DENDROBIEAE.

Tribu GYMBIDIEAE.

o) Inflorescencia naciendo debajo del brote hojoso; labelo con una larga callosidad, articulado móvilmente con el pie.

Tribu MAXILLARIEAE.

o) Inflorescencia naciendo más arriba que el brote hojoso; labelo sin larga callosidad, inmóvil en su articulación con el pie.

Tribu ONCIDIEAE.

n) Plantas monopodiales.

Tribu SARCANTHEAE.

Nota: Las tribus entre paréntesis son importantes en el antiguo continente y poseen especies de cultivo frecuente. 